\title{
Phonological Disorder
}

Carney Sotto ${ }^{1}$, Lexi Perrault ${ }^{2}$ and

${ }^{2}$ University of Cincinnati, Cincinnati, OH, USA

${ }^{3}$ Mercy Family Center, Metarie, LA, USA

Christina Nessler ${ }^{3}$

${ }^{1}$ College of Allied Health Sciences, University of See speech sound disorder.

Cincinnati, Cincinnati, OH, USA 